\title{
Decomposition Analysis of Energy Efficiency in China's Beijing-Tianjin-Hebei Region
}

\author{
Wei Li ${ }^{1,2 *}$, Huixia Zhang $^{1}$ \\ ${ }^{1}$ School of Economics and Management, North China Electric Power University, \\ Baoding, Hebei 071003, China \\ ${ }^{2}$ Philosophy and Social Science Research Base of Hebei Province, North China Electric Power University, \\ Baoding, Hebei 071003, China
}

Received: 10 August 2016

Accepted: 22 September 2016

\begin{abstract}
This manuscript first gives a separate decomposition analysis on the factors that affect regional energy efficiency in Beijing, Tianjin, and Hebei, China, during 2005-12 based on the logarithmic mean divisia index (LMDI) model, and then makes an in-depth investigation on impact factors in the Beijing-TianjinHebei (BTH) region of China. Energy efficiency is decomposed into carbon productivity, carbon emission coefficient, energy structure, energy intensity, economic output, and reciprocal effect of per capita energy consumption. Different impact factors in various areas have diverse influences on energy efficiency due to the evident regional differences in Beijing, Tianjin, and Hebei. On the whole, the primary positive driver of energy efficiency is the economic output in the BTH region, followed by carbon productivity, carbon emission coefficient, and energy structure. However, energy intensity and the reciprocal effect of per capita energy consumption are the major inhibitory factors. Finally, we emphasize a series of policy implications to speed up the achievement of China's $12^{\text {th }}$ Five-Year Plan goal. It also has the vital practical significance of carrying out energy policy and a low-carbon economic development strategy in the BTH region in the future.
\end{abstract}

Keywords: logarithmic mean divisia index (LMDI) method, Beijing-Tianjin-Hebei region, energy efficiency, decomposition analysis, low-carbon economy

\section{Introduction}

Climate change is one of the significant conundrums of the world and has already drawn attention on a global scale. On the other hand, the international community is constantly taking action to reach an agreement on reducing greenhouse gas emissions. The rapid development of

*e-mail: ncepulw@126.com
China's economy is bound to add energy consumption, thus the improvement of energy efficiency by promoting technological progress is an effective approach to cut down carbon emissions fundamentally. The joint development of the Beijing-Tianjin-Hebei (BTH) region has been given great importance by China's State Council due to the Beijing-Tianjin-Hebei located in the Bohai Bay region. According to the latest data from the China Statistical Yearbook, the GDP has risen from 688.63 billion Yuan to 2,133.08 billion Yuan in Beijing in the course of 2005-14, up from 369.76 billion Yuan to 1,527.69 billion Yuan in 
Tianjin, and from 1,009.61 billion Yuan to 2,942.12 billion Yuan in Hebei [1]. In virtue of rapid economic development and its special location, the BTH region is attracting more and more attention. Currently, haze has become the worst atmospheric pollution problem in China. As a result of this phenomenon, there fewer than $1 \%$ over the 500 biggest cities have the power to reach the air quality standards proposed by the World Health Organization in China, and seven cities among them, which are located in the BTH region, join the ranks of the 10 most polluted cities in the world. The serious haze has terrible adverse effects on economic development in the BTH region and on people's health. Energy consumption in the BTH region of China based on the China Statistical Yearbook is rising at an annual growth rate of $5.23 \%$, a transition from 134.61 million tons to 192.27 million tons, on the scope of 2005-12 [2]. The reasons for this phenomenon are in particular combustion of a great quantity of fossil fuels such as coal and oil, and inappropriate production modes and lifestyles. Therefore, it is of great significance to improve regional energy efficiency and carry out the work of energy conservation and emission reduction to analyze rationally the differences of energy efficiency and influencing factors in the BTH region.

Nowadays, the index decomposition analysis approach, namely IDA, has been proverbially employed to probe into the factors affecting energy consumption growth [3]. Plenty of scholars have adopted the index decomposition analysis (IDA) [4-6]. For instance, Ang et al. emerged from the development and utilization of IDA methods and introduced another method called the logarithmic mean divisia index (LMDI) for a lot of applications [79]. In addition, some researchers have conducted a multitude study on carbon emissions by using structural decomposition analysis (SDA) [10-12]. LMDI, adopted for the decomposition of multiple factors, has the power to deal with zero residual errors and imperfect data sets, so energy consumption can be decomposed quantitatively into an array of factors $[3,8-9,13]$. Zhang et al. explored the changes of carbon emissions in Beijing province and found that energy intensity plays a major role in reducing carbon emissions [14]. Shao et al. investigated the primary factors governing carbon emissions related to energy consumption from industry in Tianjin and determined that the improvement of energy efficiency is the most effective way to achieve energy conservation and emission reductions in industry [15]. In addition, a few scholars have analyzed the specific influence of various factors on carbon emissions based on the regional change [16-19]. Ang et al. and Wang et al. have pointed out that carbon emissions are principally caused by economic growth with the LMDI decomposition approach [20-21]. Wen et al. analyzed influencing factors of China's energy-related $\mathrm{CO}_{2}$ emissions by using an extended STIRPAT model [22]. Zhou et al. discussed energy efficiency of seven areas in China as well as carbon emissions manufactured in virtue of thermoelectric power generation [23]. Balezentis employed the LMDI method to deliberate the factors dominating the Lithuanian energy intensity [24].
Wen and Liu employed the extended STIRPAT model to research the future footprint of $\mathrm{CO}_{2}$ emissions in the BTH region [25]. Lin et al. probed into what factors influenced fossil fuel demand by using the LMDI method and assessed the potential space of fossil fuel conservation [26]. Currently, there are mainly two types of research on energy efficiency in China: some papers have emphasized formulating policy in one industrial sector [27-29] while others have explored measures and suggestions in one region [30-32]. Moreover, technological innovation mirrors the phenomenon that one company has the ability to produce a commodity by consuming minor energy [33-34].

The majority of existing literature is widely concentrated in the analytical level of carbon emissions and carbon emission intensity. Nevertheless, there is seldom research specializing in regional energy efficiency from various sectors in the BTH region. This paper makes decomposition analysis of factors affecting energy efficiency in diverse provinces in the BTH region, and we decompose energy efficiency into carbon productivity effect, carbon emission coefficient effect, energy structure effect, energy intensity effect, economic output effect, and reciprocal effect of per capita energy consumption within the scope of 2005-12 in the BTH region of China by applying LMDI, which not only can overcome the uniqueness of decomposition, but also generate in-depth analysis on the impact factors governing energy efficiency in different areas and diverse sectors. Under the background of BTH regional integration, this research provides a scientific basis for policymakers to lay down pertinence measures of regional energy saving and emission reduction so as to speed up the achievement of China's $12^{\text {th }}$ Five-Year Plan goal of energy intensity slashes of $16 \%$ compared with 2010, and "China's carbon emissions per unit of GDP would be reduced by $60-65 \%$ in 2030 from the 2005 level, the share of non fossil energy accounting for about $20 \%$ of primary energy consumption."

The remaining portion of this study is arranged as follows: Section 2 introduces the extended logarithmic mean divisia index approach, Section 3 concisely states the data sources in this study, Section 4 expounds on the comprehensive decomposition results and discussion, and Section 5 sums up the principal conclusions and comes up with a series of pertinent policy suggestions.

\section{Methodology}

Yoichi Kaya first came up with the following Kaya identity in order to decompose carbon emissions:

$$
C=\frac{C}{E} \times \frac{E}{G D P} \times \frac{G D P}{P} \times P
$$

...where $C$ means carbon emissions, $E$ represents the whole energy consumption, GDP denotes gross domestic product, and $P$ expresses population scale. 
According to the definition of energy efficiency, we record $I$ as energy efficiency, namely,

$$
I=\frac{Q}{E}
$$

For the convenience of research on energy efficiency in different sectors and various areas, this paper has decomposed energy efficiency into carbon productivity effect, carbon emission coefficient effect, energy structure effect, energy intensity effect, economic output effect, and reciprocal effect of per capita energy consumption six factors. Due to the Kaya identity being just appropriate for general research of one state or area, we have improved the Kaya identity as follows:

$I=\frac{Q}{E}=\frac{\sum_{i, j} Q_{i j}}{E}=\sum_{i, j} \frac{Q_{i j}}{C_{i j}} \times \frac{C_{i j}}{E_{i j}} \times \frac{E_{i j}}{E_{i}} \times \frac{E_{i}}{Q_{i}} \times \frac{Q_{i}}{P_{i}} \times \frac{P_{i}}{E}$

...where $I$ mirrors energy efficiency, $Q$ means regional economic output, $E$ shows regional energy consumption, $Q_{i j}$ reflects economic output of sector $j$ in region $i, C_{i j}$ indicates carbon emissions of sector $j$ in region $i, E_{i j}$ illustrates energy consumption of sector $j$ in region $i, E_{i}$ represents energy consumption in region $i, Q_{i}$ expresses economic output in region $i$, and $P_{i}$ denotes population in region $i$.

We adopt the following simplified equation to describe regional energy efficiency:

$$
I=\sum_{i, j} I_{i, j}=\sum_{i, j} Y_{i, j} \times R_{i, j} \times e_{i, j} \times K_{i} \times H_{i} \times M_{i}
$$

We give the following specific definition within the above equation.

$-Y_{i, j}=Q_{i, j} / C_{i, j}$ denotes the economic output of per unit carbon emissions of sector $j$ in region $i$, i.e., the carbon productivity effect.

- $R_{i, j}=C_{i, j} / E_{i, j}$ denotes the carbon emission coefficient of sector $j$ in region $i$, i.e., the carbon emission coefficient effect.

- $e_{i, j}=E_{i, j} / E_{i} \quad$ denotes the ratio of energy consumption of sector $j$ in region $i$ over total energy consumption, i.e., energy structure effect.

- $K_{i}=E_{i} / Q_{i}$ denotes the energy intensity in region $i$, i.e., energy intensity effect.

- $H_{i}=Q_{i} / P_{i}$ denotes per capita GDP in region $i$, i.e., economic output effect.

- $M_{i}=P_{i} / E$ denotes the reciprocal of per capita

energy consumption in region $i$, i.e., reciprocal effect of per capita energy consumption.

In line with the above equations, the variations of regional energy efficiency from benchmark year 0 to target year $\mathrm{T}$ could be delivered as follows:

$$
\Delta I=I^{T}-I^{0}=\Delta I_{Y}+\Delta I_{R}+\Delta I_{e}+\Delta I_{K}+\Delta I_{H}+\Delta I_{M}
$$

...where $\Delta I$ illustrates the change of energy efficiency, $\Delta I_{Y}$ represents carbon productivity effect, $\Delta I_{R}$ denotes carbon emission coefficient effect, $\Delta I$ indicates energy structure effect, $\Delta I_{K}$ reflects energy intensity effect, $\Delta I_{H}$ expresses economic output effect, and $\Delta I_{M}$ means reciprocal effect of per capita energy consumption. This research makes the decomposition on regional energy efficiency by introducing the LMDI method $[3,9,13]$ and the detailed results are depicted as follows:

$$
\begin{aligned}
& \Delta I_{Y}=\sum_{i=1}^{3} \sum_{j=1}^{6}\left[L\left(\mathrm{I}_{i, j}^{T}, \mathrm{I}_{i, j}^{0}\right) \times \ln \frac{Y_{i, j}^{T}}{Y_{i, j}^{0}}\right] \\
& \Delta I_{R}=\sum_{i=1}^{3} \sum_{j=1}^{6}\left[L\left(\mathrm{I}_{i, j}^{T}, \mathrm{I}_{i, j}^{0}\right) \times \ln \frac{R_{i, j}^{T}}{R_{i, j}^{0}}\right] \\
& \Delta I_{e}=\sum_{i=1}^{3} \sum_{j=1}^{6}\left[L\left(\mathrm{I}_{i, j}^{T}, \mathrm{I}_{i, j}^{0}\right) \times \ln \frac{e_{i, j}^{T}}{e_{i, j}^{0}}\right] \\
& \Delta I_{K}=\sum_{i=1}^{3} \sum_{j=1}^{6}\left[L\left(\mathrm{I}_{i, j}^{T}, \mathrm{I}_{i, j}^{0}\right) \times \ln \frac{K_{i}^{T}}{K_{i}^{0}}\right] \\
& \Delta I_{H}=\sum_{i=1}^{3} \sum_{j=1}^{6}\left[L\left(\mathrm{I}_{i, j}^{T}, \mathrm{I}_{i, j}^{0}\right) \times \ln \frac{H_{i}^{T}}{H_{i}^{0}}\right] \\
& \Delta I_{M}=\sum_{i=1}^{3} \sum_{j=1}^{6}\left[L\left(\mathrm{I}_{i, j}^{T}, \mathrm{I}_{i, j}^{0}\right) \times \ln \frac{M_{i}^{T}}{M_{i}^{0}}\right]
\end{aligned}
$$

Furthermore, we mold parameter L:

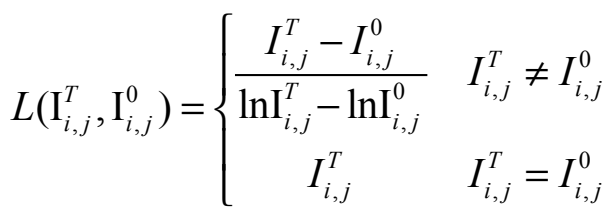


Meanwhile, the following constraints under which these equations should be executed are:

$$
Y \neq 0, \mathrm{R} \neq 0, \mathrm{e} \neq 0, \mathrm{~K} \neq 0, \mathrm{H} \neq 0, \mathrm{M} \neq 0
$$

\section{Empirical Results and Discussion}

\section{Data Source}

This study analyzes energy efficiency in the BTH region of China in the scope of 2005-12 at length. Since 2005 saw the start of the 11th Five-Year Plan, energy consumption has risen sharply along with high-speed economic development. Hence, 2005, as the representative timing for this study on regional energy efficiency, is considered the standard year. Meanwhile, considering the availability of the latest year data from the statistical yearbook, we take 2012 as a comparison.

Taking the category of sectors and energy from the 2005-13 China Statistical Yearbooks [2], this paper discusses energy consumption from coal, coke, crude oil, gasoline, kerosene, diesel oil, fuel oil, and natural gas in different industrial sectors, including agriculture; industry; construction; transportation, storage, and postal services; wholesale retail trade and food services; and other sectors in various regions.

The relevant data with GDP, regional population, regional economic output, and regional sectoral energy consumption are employed from the China Statistical Yearbook and China Energy Statistical Yearbook [2]. We provide the uniform standards in the process of calculation. For instance, the GDP and regional economic output are measured in billions of yuan at constant 2005 levels. The energy consumption units from all sectors are unified as millions of tons of standard coal, and energy consumption in all sectors are turned into ton coal equivalents (tec) based on the Intergovernmental Panel on Climate Change (IPCC) [35]. Table 1 represents carbon dioxide emission coefficients from various fossil fuels.

As illustrated in Fig 1, it is clear that the BTH regional energy efficiency in 2005-12 shows a rising tendency in different degrees. Specifically, in 2012 energy efficiency in Beijing, which is obviously higher than the overall level of BTH energy efficiency, reaches the highest value with the fastest-growing speed, an average annual growth rate of $15.32 \%$ (from 0.2544 million yuan/tce in 2005 to 0.6900 million yuan/tce in 2012). Energy efficiency in Tianjin appears to have a slight lower growth rate than

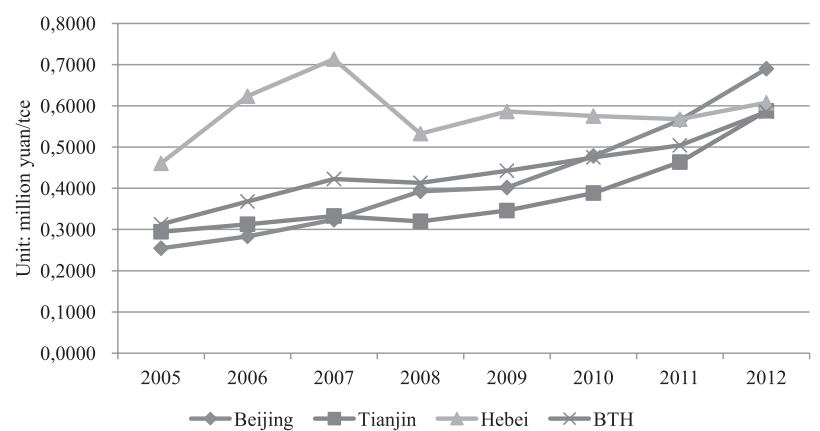

Fig. 1. Actual energy efficiency in the Beijing-Tianjin-Hebei region (2005-2012).

that in Beijing - an increase from 0.2945 million yuan/ tce in 2005 to 0.5879 million yuan/tce in 2012. It is apparent that energy efficiency in Tianjin emerges as a downward trend during 2007-08, and yet continuously increases subsequently, especially in the period of 201012 , which rises dramatically at the average annual growth rate of $10.38 \%$. However, in spite of the maximal initial value of energy efficiency in Hebei, it shows the minimum average annual growth rate of $4.03 \%$, an increase from 0.4606 million yuan/tce in 2005 to 0.6074 million yuan/ tce in 2012. As a whole, overall energy efficiency in the BTH region, which exhibits an annual average growth rate of $9.38 \%$ (from 0.3125 million yuan/tce in 2005 to 0.5853 million yuan/tce in 2012), has been on an upward trend apart from 2007-08. Seen from above, the major reason why overall energy efficiency in the BTH region rises slowly is that energy efficiency in Hebei has always seen a sluggish growth rate. The annual average growth rate of energy efficiency in Beijing is about 3.8 times as much as that of Hebei, while in Tianjin it is 2.6 times that of Hebei. Therefore, if we intend to improve the overall energy efficiency in the BTH region, it is necessary to emphasize rising energy efficiency in Hebei province.

\section{Energy Situation of the Beijing-Tianjin-Hebei Region}

Energy consumption in the BTH region of China grows dramatically along with the rapid development of China's economy. The specific energy consumption in the BTH region of China over the period of 2005-12 is exhibited in Table 2 and Fig. 2.

As described in Fig. 2, energy consumption in the $\mathrm{BTH}$ region takes on a yearly ascending trend. To be more specific, energy consumption in Beijing rises from

Table 1. $\mathrm{CO}_{2}$ emission coefficients.

\begin{tabular}{|c|c|c|c|c|c|c|c|c|}
\hline Sources & Coal & Coke & Crude oil & Gasoline & Kerosene & Diesel oil & Fuel oil & Natural gas \\
\hline $\begin{array}{c}\mathrm{CO}_{2} \text { emission } \\
\text { coefficients }\end{array}$ & 1.647 & 2.848 & 3.152 & 3.045 & 3.174 & 3.150 & 3.064 & 21.670 \\
\hline
\end{tabular}

Source: IPCC and the National Coordination Committee Office on Climate Change and Energy Research Institute under the National Development and Reform Commission. 
Table 2. Energy consumption in the Beijing-Tianjin-Hebei region (2005-12; unit: Mtce).

\begin{tabular}{|cccccccccc|}
\hline Province & 2005 & 2006 & 2007 & 2008 & 2009 & 2010 & 2011 & 2012 \\
\hline Beijing & 19.94 & 21.67 & 23.04 & 22.22 & 22.77 & 23.70 & 21.97 & 20.65 \\
\hline Tianjin & 17.25 & 19.11 & 21.03 & 22.18 & 23.97 & 23.33 & 24.78 & 24.55 \\
\hline Hebei & 97.42 & 106.51 & 111.14 & 123.53 & 125.97 & 130.68 & 146.93 & 147.08 \\
\hline BTH & 134.61 & 147.29 & 155.21 & 167.93 & 172.72 & 177.71 & 193.68 & 192.27 \\
\hline
\end{tabular}

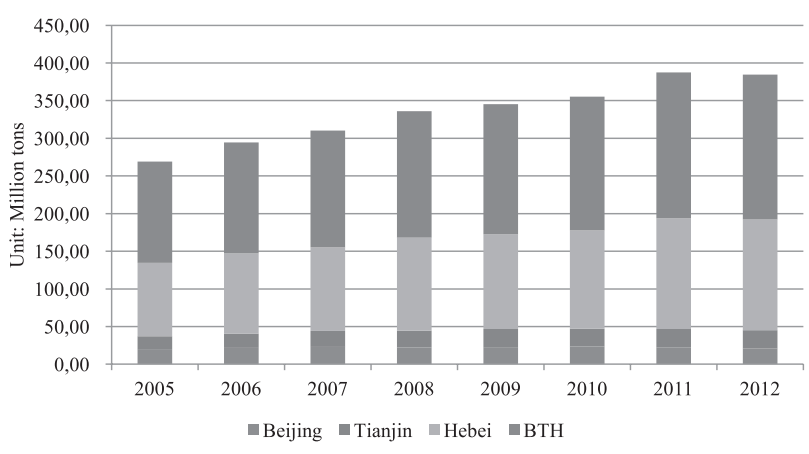

Fig. 2. Energy consumption in the Beijing-Tianjin-Hebei region (2005-2012).

19.94 million tons in 2005 to 20.65 million tons in 2012 with the annual average growth rate of $0.50 \%$. Energy consumption in Tianjin adds from 17.25 million tons in 2005 to 24.55 million tons in 2012 with the annual average growth rate of $5.17 \%$ while energy consumption in Hebei increases at an average growth rate of $6.06 \%$ (from 97.42 million tons in 2005 to 147.08 million tons in 2012). Energy consumption in the BTH region grows at an average growth rate of $5.23 \%$ - an increase from 134.61 million tons in 2005 to 192.27 million tons in 2012. It is evident that energy consumption in Hebei far exceeds that of Beijing and Tianjin. For instance, energy consumption of Hebei in 2005 is about 4.89 and 5.65 times as much as that of Beijing and Tianjin, respectively, while is about 7.12 and 5.99 times that in 2012. In addition, energy consumption of Tianjin has been lower than that of Beijing in the course of 2005-08, whereas it begins to surpass that of Beijing in 2009. According to the above analysis, we can know that high-speed energy consumption in Hebei is the primary reason leading to high energy consumption in the BTH region.

\section{Decomposition Analysis}

According to the LMDI decomposition formula [10], we figured out the different contribution values of carbon productivity effect, carbon emission coefficient effect, energy structure effect, energy intensity effect, economic output effect, and reciprocal effect of per capita energy consumption for energy efficiency in the BTH region over the period of 2005-12, taking two adjacent years as the sample interval. The calculation results are depicted in Table 3.
Table 3 illustrates that carbon productivity effect with the contribution value of 0.4022 personates the paramount positive role on improving energy efficiency in Beijing, followed by the reciprocal effect of per capita energy consumption (0.1767), economic output effect (0.2608), and carbon emission coefficient effect (0.0333), while energy intensity effect with the contribution value of -0.4011 generates the leading negative impact on energy efficiency, followed by energy structure effect $(-0.0364)$. Economic output effect (0.3264) reflects the uppermost positive driving force on energy efficiency in Tianjin, followed by carbon productivity effect $(0.2855)$, energy structure effect (0.0354), and carbon emission coefficient effect (0.0079), whereas energy intensity effect $(-0.3238)$ takes the overriding negative role on energy efficiency, followed by the reciprocal effect of per capita energy consumption (-0.0381). Economic output effect (0.5411) has the principal impact of boosting energy efficiency in Hebei, followed by energy structure effect $(0.1828)$ and carbon productivity effect $(0.1492)$, yet the reciprocal effect of per capita energy consumption $(-0.3871)$ has the largest power-to-rise energy efficiency, energy intensity effect $(-0.3369)$, and carbon productivity effect $(-0.0024)$ following.

As seen in Fig. 3, it is obvious that the change tendency of each effect in Tianjin, by and large, is basically in line with that of the BTH region. In general, economic output effect has always been in a positive position to progressively push up energy efficiency in different provinces, which leads to the overall variation of energy efficiency in the $\mathrm{BTH}$ region to a much greater extent. Besides, the various impact factors appear to have individual differences both in size and property.

On the whole, from the view of regional integrating, economic output effect $(0.3807)$ is the cardinal factor to enhance energy efficiency in the BTH region over the period starting 2005 and ending 2012, followed by carbon productivity effect $(0.2579)$, carbon emission coefficient effect (0.0149), and energy structure effect (0.0078). In contrast, energy intensity effect $(-0.2919)$ manifests the top-drawer influence on restraining energy efficiency while reciprocal effect per capital energy consumption $(-0.0966)$ pertains to the next in importance.

\section{Carbon Productivity Effect}

Carbon productivity effect mirrors the industrial GDP per unit of carbon emissions. Fig. 4 reveals the specific 
Table 3. Decomposition results of the influence factors of energy efficiency (2005-12).

\begin{tabular}{|c|c|c|c|c|c|c|c|}
\hline \multicolumn{2}{|c|}{ Province } & Carbon & Carbon emission & Energy & Energy & Economic & Reciprocal effect of per \\
\hline \multirow{8}{*}{ Beijing } & $2005-06$ & 0.0283 & 0.0006 & -0.0087 & -0.0187 & 0.0303 & -0.0029 \\
\hline & $2006-07$ & 0.0414 & -0.0012 & -0.0022 & -0.0398 & 0.0445 & -0.0024 \\
\hline & $2007-08$ & 0.0723 & -0.0033 & -0.0011 & -0.0565 & 0.0240 & 0.0336 \\
\hline & 2008-09 & 0.0096 & -0.0004 & 0.0136 & -0.0261 & 0.0164 & -0.0039 \\
\hline & $2009-10$ & 0.0782 & -0.0015 & -0.0267 & -0.0481 & 0.0423 & 0.0325 \\
\hline & $2010-11$ & 0.0883 & -0.0015 & 0.0218 & -0.1130 & 0.0586 & 0.0325 \\
\hline & 2011-12 & 0.0841 & 0.0407 & -0.0332 & -0.0989 & 0.0447 & 0.0874 \\
\hline & $2005-12$ & 0.4022 & 0.0333 & -0.0364 & -0.4011 & 0.2608 & 0.1767 \\
\hline \multirow{8}{*}{ Tianjin } & $2005-06$ & 0.0185 & -0.0002 & -0.0147 & -0.0094 & 0.0313 & -0.0072 \\
\hline & 2006-07 & 0.0204 & -0.0004 & 0.0026 & -0.0217 & 0.0408 & -0.0217 \\
\hline & $2007-08$ & -0.0104 & -0.0025 & 0.0715 & -0.0619 & 0.0619 & -0.0715 \\
\hline & 2008-09 & 0.0275 & -0.0015 & -0.0012 & -0.0117 & 0.0231 & -0.0102 \\
\hline & 2009-10 & 0.0435 & -0.0009 & 0.0415 & -0.0848 & 0.0542 & -0.0109 \\
\hline & 2010-11 & 0.0746 & 0.0005 & -0.0173 & -0.0608 & 0.0688 & 0.0093 \\
\hline & 2011-12 & 0.1113 & 0.0130 & -0.0471 & -0.0734 & 0.0464 & 0.0741 \\
\hline & $2005-12$ & 0.2855 & 0.0079 & 0.0354 & -0.3238 & 0.3264 & -0.0381 \\
\hline \multirow{8}{*}{ Hebei } & $2005-06$ & 0.1663 & -0.0036 & -0.1543 & -0.0249 & 0.0690 & 0.1102 \\
\hline & 2006-07 & 0.0908 & -0.0008 & -0.0034 & -0.0857 & 0.1098 & -0.0207 \\
\hline & $2007-08$ & -0.1824 & 0.0018 & 0.2070 & -0.0351 & 0.0961 & -0.2679 \\
\hline & 2008-09 & 0.0546 & -0.0010 & 0.0057 & -0.0302 & 0.0376 & -0.0131 \\
\hline & $2009-10$ & -0.0103 & -0.0009 & 0.0851 & -0.0763 & 0.0845 & -0.0934 \\
\hline & $2010-11$ & -0.0063 & -0.0012 & 0.0296 & -0.0379 & 0.1007 & -0.0923 \\
\hline & 2011-12 & 0.0365 & 0.0034 & 0.0130 & -0.0467 & 0.0435 & -0.0098 \\
\hline & $2005-12$ & 0.1492 & -0.0024 & 0.1828 & -0.3369 & 0.5411 & -0.3871 \\
\hline \multirow{8}{*}{ BTH } & 2005-06 & 0.0558 & -0.0004 & -0.0461 & -0.0173 & 0.0428 & 0.0206 \\
\hline & 2006-07 & 0.0558 & -0.0012 & -0.0043 & -0.0491 & 0.0633 & -0.0098 \\
\hline & 2007-08 & -0.0096 & 0.0002 & 0.0437 & -0.0359 & 0.0602 & -0.0679 \\
\hline & 2008-09 & 0.0299 & -0.0007 & 0.0057 & -0.0252 & 0.0293 & -0.0098 \\
\hline & 2009-10 & 0.0331 & -0.0005 & 0.0297 & -0.0647 & 0.0629 & -0.0279 \\
\hline & $2010-11$ & 0.0298 & -0.0007 & 0.0040 & -0.0432 & 0.0778 & -0.0386 \\
\hline & 2011-12 & 0.0632 & 0.0181 & -0.0249 & -0.0564 & 0.0446 & 0.0367 \\
\hline & $2005-12$ & 0.2579 & 0.0149 & 0.0078 & -0.2919 & 0.3807 & -0.0966 \\
\hline
\end{tabular}

impact of carbon productivity effect on energy efficiency in different regions. We can discover that carbon productivity effect provides a positive driving force on rising energy efficiency in Beijing during 2005-12. At this stage, where GDP in Beijing grows quickly at an average annual growth rate of $14.47 \%$, an increase from 698.13 billion yuan in 2005 to 1797.82 billion yuan in 2012 , while carbon emissions in Beijing rise at an average annual growth rate of $0.25 \%$ (from 44.86 million tons to 45.65 million tons), which immensely illustrates that growth rate of GDP in Beijing far surpasses the increment velocity of carbon emissions.

According to Fig. 4, it is apparent that carbon productivity effect has been engendered the positive 


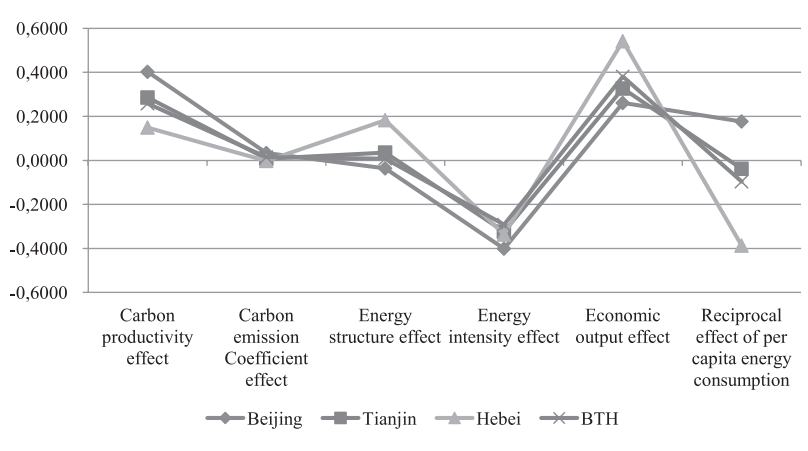

Fig. 3. The decomposition on energy efficiency in the BeijingTianjin-Hebei (2005-2012).

impact on energy efficiency in Tianjin from 2005-12 (apart from that of 2008: -0.0104). The GDP of Construction in Tianjin has increased from 23.07 billion to 29.09 billion yuan during 2007-08, with the growth rate of $26.12 \%$ when carbon emissions of construction adds from 1.10 million tons to 2.45 million tons with a growth rate of $223.08 \%$ based on data analysis. The growth rate of carbon emissions of Construction is almost 8.54 times as much as GDP. Thus it can be seen that carbon emissions of Tianjin expand dramatically owing to the rapid development of construction.

The carbon productivity effect is negative on boosting energy efficiency in Hebei in the scope of 2007-08 and 2009-11, yet positive during 2005-07, 2008-09, and 2011-12 (Fig. 4). Additionally, it is evident that carbon productivity effect with the contribution value of -0.1824 exerted an enormous negative function on energy efficiency in Hebei during 2007-08. Besides, what we can gain is that the GDPs of agriculture, wholesale retail trade, and food services and other sectors in Hebei go from 608.99 billion to 699.77 billion yuan in 2007-08 in line with data analysis, an increase by $14.91 \%$, while carbon emissions run correspondingly from 7.55 million tons to 13.93 million tons, an increase of $84.51 \%$. This phenomenon accounts for the fact that Hebei province puts an emphasis on a rapidly expanding economy rather than dealing with timely environmental degradation caused by carbon emissions, which brings about incremental speeds of carbon emissions being 5.7 times as much as that of GDP, directly leading to low energy efficiency in Hebei.

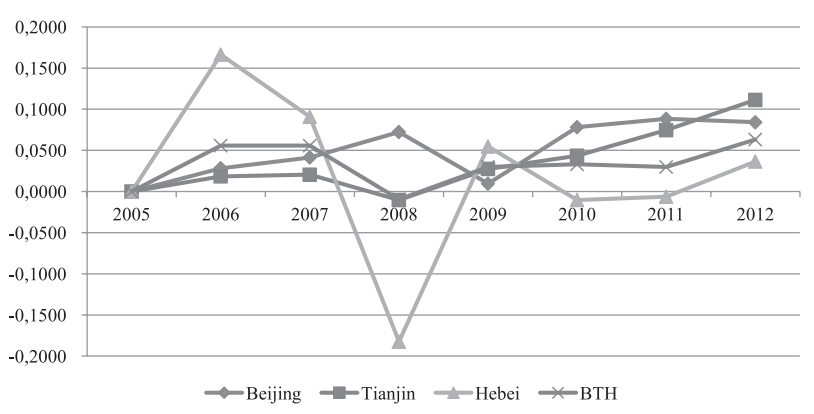

Fig. 4. Carbon productivity effect on energy efficiency in the Beijing-Tianjin-Hebei (2005-2012).
In summary, our results show evidence that the carbon productivity effect personifies the positive character of boosting the overall energy efficiency in the BTH region during 2005-12 (except for 2008, whose contribution value is -0.0096 , due mainly to the lack of regulatory measures on carbon emissions during 2007-08 in Hebei and causing carbon emissions of certain sectors to show a soaring increase).

In short, only by focusing on Hebei can we improve the overall energy efficiency in the BTH region on the basis of the above analysis of carbon productivity effect.

\section{Carbon Emission Coefficient Effect}

The carbon emission coefficient effect refers to the share of carbon emissions in the industry over energy consumption. The detailed impact of carbon emission coefficient effect on energy efficiency in each region is demonstrated in Fig. 5. It is explicit that carbon emission coefficient effect has always taken a negative role on energy efficiency in Beijing in the course of 2006-11. The main reason is that energy consumption of Beijing during this period ascends from 21.67 million tons to 21.97 million tons, while carbon emissions descend from 48.39 million tons to 46.71 million tons. Meanwhile, as Fig. 4 illustrates, we can acquire that the contribution value of carbon emission coefficients during 2011-12 in Beijing is 0.0407 . Moreover, according to data analysis, we can also chalk up that energy consumption in Beijing lessens from 21.97 million tons to 20.65 million tons during 201112 , with a growth rate of $-6.01 \%$. Nevertheless, carbon emissions, which has not received relevant control at this stage, are reduced accordingly from 46.71 million tons to 45.65 million tons at $-2.28 \%$.

In addition, Fig. 5 shows that the carbon emission coefficient effect has a negative impact on energy efficiency in Tianjin in the scope of 2005-10. Specifically speaking, energy consumption in several sectors covering agriculture, industry, construction and transportation, and storage and postal services goes up tempestuously at an average annual growth rate of $7.20 \%$ (from 14.57 million tons to 20.63 million tons), and the corresponding carbon emission rises at an average annual growth rate of $7.55 \%$ (from 34.50 million tons to 49.64 million tons) at the same time. Apparently, the growth rate of carbon emissions

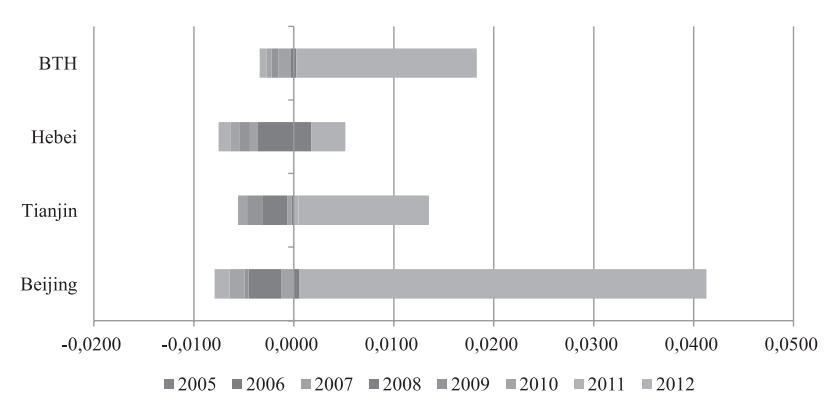

Fig. 5. Carbon emission coefficient effect on energy efficiency in the Beijing-Tianjin-Hebei (2005-2012). 
is greater than energy consumption, which explains adequately why the carbon emission coefficient effect has a positive impact on energy efficiency. Moreover, energy consumption in the remaining sectors increase slightly at an average annual growth rate of $0.13 \%$ (from 2.68 million to 2.70 million tons), whereas carbon emissions decrease from 5.76 million to 5.71 million tons - an increase with an average annual growth rate of $-0.20 \%$. Seen from the data analysis, owing to the reduction in carbon emissions accompanied by the increase of energy consumption from business and other sectors in Tianjin during 2005-10, the carbon emission coefficient effect produces a negative driving force on energy efficiency in Tianjin. On the contrary, the dominating reason why the carbon emission coefficient effect is positive on energy efficiency in Tianjin during 2010-12 is that carbon emissions rise with an average annual growth rate of $4.58 \%$ (from 55.34 million to 60.53 million tons) when energy consumption goes up with the average annual growth rate of $2.58 \%$ (from 23.33 million to 24.55 million tons), which indicates that increment speed of carbon emissions is nearly 1.8 times as much as energy consumption.

In accordance with Fig. 5, the contribution of carbon emission coefficient effect on energy efficiency in Hebei was negative in 2005-07 and 2008-11, which states that the growth rate of carbon emissions is slower than that of energy consumption, resulting in high energy efficiency, while 2007-08 and 2011-12 saw just the opposite. Specifically, we can elicit that carbon emissions in Hebei increased by $0.60 \%$ from 385.12 million to 387.43 million tons during 2011-12 by data analysis, a stage where energy consumption runs from 146.93 million to 147.08 million tons with a growth rate of $0.10 \%$.

From a regional integration standpoint, the ranging tendency of carbon emission coefficient effect on energy efficiency in the BTH region, an analogous trend of that in Hebei taking shape with various contribution values, can be found thereafter. In particular, the carbon emission coefficient effect acts as a negative part on energy efficiency in the BTH region in the course of 2005-07 and 2008-11, which indicates that carbon emissions in the BTH region grow slower than energy consumption so that we can boost energy efficiency, while in the periods 200708 and 2011-12 it was just the opposite. Taking the data analysis during 2011-12, for instance, carbon emissions in the BTH region achieve growth of $0.61 \%$ - from 490.59 million to 493.60 million tons - when energy consumption lessens from 193.68 million to 192.27 million tons with a growth rate of $0.72 \%$. In a word, despite the decrease of energy consumption in both Beijing and Tianjin during 2011-12, only Hebei responded to an increase of energy consumption, which leads directly to the overall carbon emissions in the BTH region embodying an upward trend.

In brief, if we intend to improve the overall energy efficiency in the BTH region as soon as possible, we need to pay more attention to command energy consumption in Hebei in order to further reduce carbon emissions based on the analysis of carbon emission coefficient effect.

\section{Energy Structure Effect}

Energy structure effect is defined as the ratio of energy consumption in one sector accounting for total energy consumption in all sectors from the province in the paper, and it mirrors immediately the characteristics of regional industry structure. It is thoroughly necessary for some provinces with the diminutive contribution to energy efficiency to speed up energy structure adjustment for rising energy utilization efficiency.

According to the carbon emission coefficient in Table 1 , we can reach a conclusion that there are different carbon emissions from various kinds of energy. As Fig. 6 demonstrates, coal, as the dominating source of energy consumption in the BTH region directly determining the change of overall energy consumption, accounts for more than $75 \%$ all the time, followed by oil with $17 \%$, while natural gas is very small in proportion. Since the 11th Five-Year Plan was executed, various areas not only have quickened their steps of economic development, but have also stimulated energy consumption - especially in the period of rapid development of the second industry in the BTH region, as coal consumption has grown by leaps and bounds. The most straightforward reason why energy structure effect has had a negative impact on energy efficiency in the BTH region during 2005-07 is that coal consumption has increased sharply owing to the rapid development of the second industry at this stage. Moreover, the BTH region brings forth a slow-growth trend of energy consumption due to the reduction in coal consumption to a very large extent as a result of the 2008 international finance crisis.

Fig. 7 displays the diverse impact of energy structure effect on energy efficiency in the various regions. It is evident that the energy structure effect generates a negative driving force on energy efficiency in Beijing in the course of 2005-12 (apart from 2008-09 and 2010-11). In addition, construction (0.0152), and transportation, storage, and postal services (0.0049) have had a positive impact on energy efficiency in Beijing from 2005 to 2012, while the remaining sectors, including agriculture, industry, wholesale retail trade, and food services and others possess the negative contribution value of -0.0031 ,

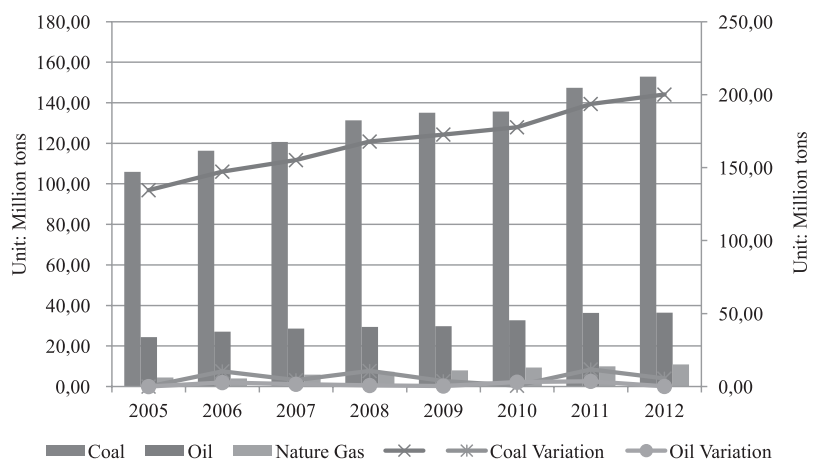

Fig. 6. Consumption and change quantity of coal, oil and natural gas in the Beijing-Tianjin-Hebei (2005-2012). 


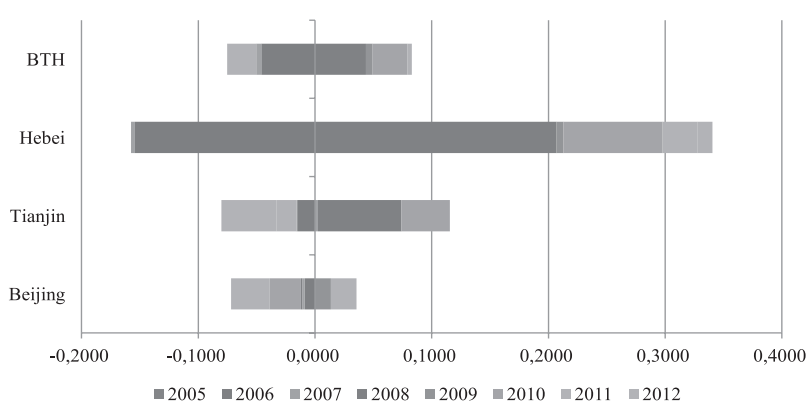

Fig 7. Energy structure effect on energy efficiency in the BeijingTianjin-Hebei (2005-2012).

$-0.0173,-0.0167$, and -0.0195 , respectively, which illustrates the extremely unreasonable industrial structure in Beijing, particularly industry - which urgently needs to adjust.

In addition, the energy structure effect exerted a positive driving force on energy efficiency in Tianjin during 2006-08 and 2009-10, while the remaining years are just the opposite. We also can gain from the data analysis that the majority of sectors such as agriculture, industry, construction, transportation, storage, postal services, and others in Tianjin in the course of 2005-12 possess positive contribution values at $0.0015,0.0004,0.0393,0.0004$, and 0.0732 , respectively (except for wholesale retail trade and food services with their negative contribution values of -0.0793). This reflects on the fact that there exists a comparatively rational industrial structure in Tianjin. Furthermore, it can be discovered that the contribution value of industry in Tianjin merely reaches 0.0004 , which mirrors it still to be further conducted industry structure adjustment so as to improve energy efficiency.

In addition, the energy structure effect plays a positive role on energy efficiency in Hebei within the scope of 2005-12 (apart from the period of 2005-07). According to data analysis, certain sectors in Hebei covering industry (-0.0001) and transportation, storage, and postal services $(-0.0005)$ produce a negative driving function on energy efficiency while the remaining sectors containing agriculture (0.1440), construction (0.0012), wholesale retail trade, and food services $(0.0300)$ and others $(0.0082)$ have a positive impact. This phenomenon declares that agriculture makes the supreme contribution to boosting energy efficiency in Hebei and it is very necessary for industry to carry out in-depth industry structure adjustment in order to raise energy efficiency.

From a regional integration perspective, energy structure effect plays a positive driving force on the overall energy efficiency in the BTH region during 200711 , and yet is negative during 2005-07 and 2011-12. Specifically, agriculture (0.0598), construction (0.0310), transportation, storage, and postal services $(0.0005)$ have a positive impact on the overall energy efficiency in the BTH region as seen from the data analysis. Nevertheless, industry (-0.0002), wholesale retail trade, food services $(-0.0572)$, and others $(-0.0289)$ are just the opposite, which accounts for the BTH region having an improper industry structure. For the moment, the government suggests distributing part of industrial enterprises into Hebei on account of the development situation of Beijing in order to regulate industrial structure for the sake of improving overall energy efficiency.

In conclusion, if we want to improve overall energy efficiency in the BTH region, we should emphasize carrying out comprehensive industry structure adjustment in the first place - especially the appropriate distribution of industrial territory in the BTH region.

\section{Energy Intensity Effect}

Energy intensity paints the proportion of energy consumption in one sector over economic output and shines upon the economic benefit from energy utilization efficiency. The more detailed decomposition outcomes of energy intensity effects in different provinces during 2005-12 are characterized in Fig. 8, where we can see that energy intensity effect presented a negative driving force on suppressing energy efficiency in the BTH region from 2005 to 2010. Theoretically speaking, the reduction in energy intensity symbolizes the promotion in energy efficiency, which commonly derives from technological progress. Thus, energy efficiency in each region gets a boost to a large extent immediately.

Combining Table 3 with Fig. 3, it is clear that the energy intensity effect emerges as the top-drawer negative driving force on energy efficiency with a contribution value of -0.2919 . Meanwhile, energy intensity effect also plays the principal negative function in Beijing (-0.4011) and Tianjin (-0.3238). Nevertheless, the foremost negative factor on energy efficiency in Hebei is the reciprocal effect per capital energy consumption $(-0.3871)$, followed by energy intensity effect $(-0.3369)$ and carbon emission coefficient effect $(-0.0024)$.

Furthermore, the energy intensity effect whose contribution value is -0.1130 delineates the leading negative character on energy efficiency in Beijing during 2010-11 (Fig. 8). More specifically, the energy intensity effect of each sector in Beijing has a negative impact on energy efficiency at the same time learned from the data analysis during 2010-11. In general, energy consumption in Beijing during 2010-11 diminished from 23.70 million to 21.97 million tons, an increase of $-7.32 \%$, while

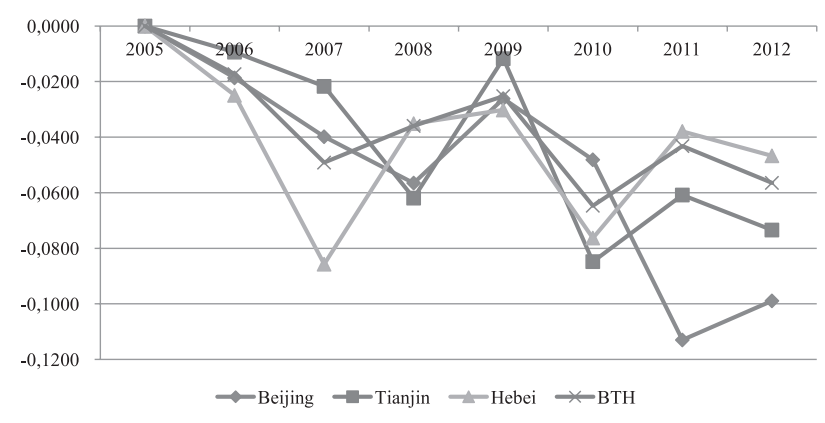

Fig. 8. Energy intensity effect on energy efficiency in the BeijingTianjin-Hebei (2005-2012). 
the corresponding GDP goes up from 1,417.80 billion to 1632.83 billion yuan, an increase of $15.17 \%$. This phenomenon expounds GDP grows by leaps and bounds on the premise of reduced energy consumption in Beijing, making sure that the energy intensity effect exerts the primary negative impact on energy efficiency. Besides, Fig. 8 reveals that Tianjin and Beijing manifests utterly a similar trend with the BTH region in the energy intensity effect. Hebei possesses the rock-bottom energy intensity effect (-0.0857) during 2006-07, which explains that GDP has an increase on the basis of decreasing energy consumption, while Tianjin owns the lowest energy intensity effect $(-0.0848)$ during $2009-10$, a stage where GDP runs from 752.19 billion to 922.45 billion yuan with a growth rate of $22.64 \%$ when energy consumption decreases from 23.97 million to 23.33 million tons. These behaviors made tremendous contributions to the minimum energy intensity effect $(-0.0647)$ in the BTH region in 2009-10, a stage where GDP rose by $18.49 \%$, from $3,696.31$ billion to $4,379.67$ billion yuan, and when energy consumption increased by $2.89 \%$, from 172.72 million to 177.71 million tons. Apparently, the growth rate of GDP is 6.4 times as much as that of energy consumption. According to further analysis, we can see that energy consumption in Hebei will continue to rise while Beijing and Tianjin see their respective increases by the large margin in GDP on the basis of the reduction of energy consumption. Therefore, in order to boost the overall energy efficiency in the BTH region, we ought to focus on guaranteeing the sharp growth of GDP in Hebei on the premise of cutting down energy consumption rather than raising GDP at the expense of enormous energy consumption.

\section{Economic Output Effect}

Economic output effect, i.e., per capita GDP effect, adequately measures the production capacity per capita as well as services from a country or region. It incarnates not only rapid national economic development, but also the average living level of people. The detailed impact of economic output effect on energy efficiency in various areas is portrayed in Fig. 9. It is apparent that economic output effect represents the positive driving force on energy efficiency in different regions in the course of 200512 , improving regional energy efficiency immediately.

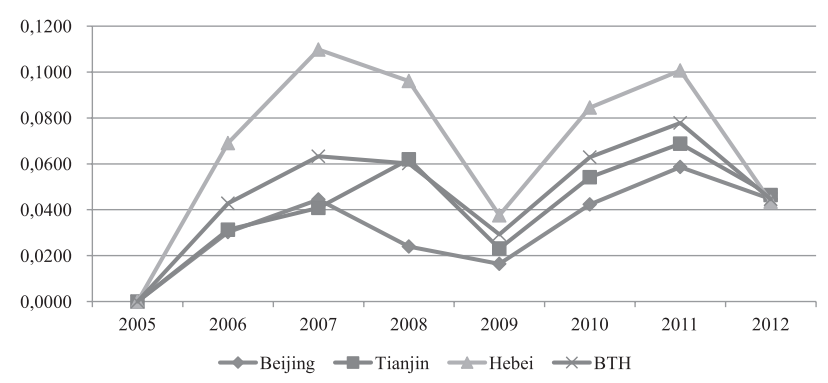

Fig. 9. Economic output effect on energy efficiency in the Beijing-Tianjin-Hebei (2005-2012).
Integrating Table 3 with Fig. 3, we can be aware of economic output effect, which is not only the primary positive driving force on energy efficiency in the BTH region with contribution value of 0.3807 , but also the leading positive driving force in Hebei (0.5411) and Tianjin (0.3264). However, carbon productivity effect is the principal positive driving force in Beijing, followed by the reciprocal effect per capital energy consumption (0.1767), economic output effect (0.2608), and carbon emission coefficient effect (0.0333).

Fig. 9 demonstrates that economic output effect produces the positive driving function on energy efficiency in each area during 2005-12, in which Beijing possesses the uppermost economic output effect with the contribution value of 0.0586 during 2010-11, as does Tianjin (0.0688). Notwithstanding, the contribution value of economic output effect in Hebei only reaches 0.1007 during 2010-11 in spite of the largest contribution value of 0.1098 over the period of 2006-07. There is no doubt that these phenomena prevailingly brought about the largest economic output effect (0.0778) in the BTH region during 2010-11. In general, GDP in the BTH region increases at an average annual growth rate of $15.54 \%$ by the data analysis in the course of 2005-12, from 2,089.91 billion to 5744.71 billion yuan, while the corresponding population rises at an average annual growth rate of $1.91 \%$, from 94.32 to 107.70 million. It is obvious that the growth rate of GDP in the BTH region is more than 8 times as much as that of population during 2005-12, which gives rise to economic output effect directly promoting the improvement of overall energy efficiency in the BTH region.

The increase of per capita GDP leads to a substantial increase in energy consumption immediately based on the analysis of economic output effect, which is exactly one of the significant factors for laying down measures to boost energy efficiency in the BTH region we must take into consideration.

\section{Reciprocal Effect per Capital Energy Consumption}

Reciprocal effect per capital energy consumption refers to the share of the population accounting for energy consumption of every sector from the area, which conveys

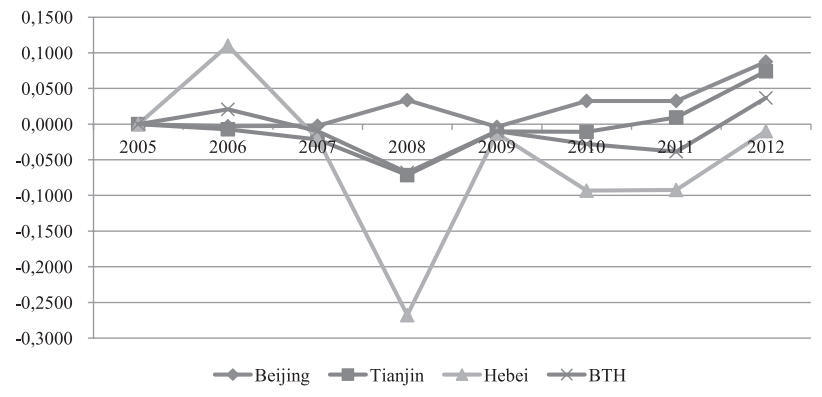

Fig. 10. Reciprocal effect per capital energy consumption on energy efficiency in the Beijing-Tianjin-Hebei (2005-2012). 
indirectly the influence of per capita energy consumption on regional energy efficiency.

Fig. 10 expresses clearly and forcibly the impact of reciprocal effect per capital energy consumption on energy efficiency in diverse provinces. We can acknowledge that reciprocal effect per capital energy consumption exerts the negative impact on energy efficiency in Beijing over the period of 2005-07 and 2008-09, which states the growth rate of the population being lower than that of energy consumption, whereas it is the positive driving force during 2007-08 and 2009-12. Furthermore, the population rose from 19.62 million to 20.69 million in Beijing during 2010-12, an average annual growth rate of $2.70 \%$, while energy consumption was reduced from 23.70 million to 20.65 million tons with an average annual growth rate of $-6.66 \%$, accordingly. It is undeniable that energy consumption is drastically reduced on the basis of everincreasing population on the scope of 2010-12, taking it for granted that the reciprocal effect per capital energy consumption has a positive impact on energy efficiency in Beijing.

In addition, reciprocal effect per capital energy consumption presented negative characteristics of energy efficiency in Tianjin during 2005-10, while it was negative in Hebei in 2006-12. There is no denying the fact that increment speed of population in Tianjin and Hebei is considerably below energy consumption. It's not difficult to find that energy consumption in Hebei keeps constantly growing with an average annual growth rate of 5.53\% over a period of 2006-12, from 106.51 million to 147.08 million tons. Thus, this means that what matters is to control continuously increasing energy consumption in Hebei.

Besides, the reciprocal effect per capital energy consumption produces a positive driving function on energy efficiency in Tianjin during 2010-12, while it was positive in Hebei in 2005-06. According to the data analysis, energy consumption rose from 23.33 million to 24.55 million tons with an average annual growth rate of $2.58 \%$ in Tianjin during 2010-12, when the population grew from 12.99 to 14.13 million at an average annual growth rate of $4.29 \%$. We can see that the growth speed of population far exceeded energy consumption, which is the straightforward reason why the reciprocal effect per capital energy consumption has a positive impact on energy efficiency.

From the regional integration viewpoint, the impact of reciprocal effect per capital energy consumption on energy efficiency in the BTH region was negative during 200611 , and yet was positive in 2005-06 and 2011-12, which illustrates that energy consumption unceasingly increased during 2006-11 in the BTH region. Seen from data analysis, the population grew from 95.74 to 106.14 million with an average annual growth rate of $2.08 \%$ in the course of 2006-11 in the BTH region, while the corresponding energy consumption rises at an average annual growth rate of $5.63 \%$ - from 147.29 to 193.68 million tons. It is clear that the growth speed of energy consumption was about 2.7 times as much as that of population on the scope of 2006-11 in the BTH region, making sure that the reciprocal effect per capital energy consumption exerts a negative influence on energy efficiency in the BTH region straightway so as to restrain the improvement of energy efficiency.

In accordance with the analysis of reciprocal effect per capital energy consumption, there is no doubt that we must focus on governing ever-increasing energy consumption in Hebei in order to enhance overall energy efficiency in the BTH region.

\section{Sector Analysis}

Table 4 reveals the different influences of six sectors on energy efficiency in various provinces. Apparently, agriculture in Beijing and Tianjin plays a positive role in energy efficiency, which mirrors agriculture having the power to boost regional energy efficiency. In contrast, agriculture in Hebei emerges as a negative driving force on energy efficiency, mainly because the GDP adds from 140 billion to 318.67 billion yuan in Hebei during 200512 with an average annual growth rate of $12.47 \%$ when energy consumption rises at the average annual growth rate of $21.56 \%$, from 0.98 million to 3.86 million tons, leading to low energy efficiency owing to the dependency of agricultural development on a mountain of energy consumption.

Industry appears to be a positive driving function on energy efficiency in different provinces notwithstanding, compared with remaining sectors, and we can see that industry holds an extremely small contribution value regarding energy efficiency. It declares that Industry brings about wholesale economic output by relying on a large amount of energy consumption, which is not conducive to improving overall energy efficiency. Long run leftovers, it is necessary for industry to prompt technological innovation and depend on science and engineering so that

Table 4. Contribution values of industrial structures on energy efficiency (2005-12).

\begin{tabular}{|c|c|c|c|c|c|c|}
\hline Province & Agriculture & Industry & Construction & $\begin{array}{c}\text { Transportation, storage, } \\
\text { and postal services }\end{array}$ & $\begin{array}{c}\text { Wholesale retail trade } \\
\text { and food services }\end{array}$ & Other \\
\hline Beijing & 0.0158 & 0.0426 & 0.0513 & 0.0004 & 0.1501 & 0.1754 \\
\hline Tianjin & 0.0010 & 0.0208 & -0.0135 & 0.0035 & 0.1326 & 0.1490 \\
\hline Hebei & -0.0597 & 0.0043 & 0.0879 & 0.0022 & 0.0342 & 0.0779 \\
\hline BTH & -0.0129 & 0.0067 & 0.0166 & 0.0021 & 0.1199 & 0.1404 \\
\hline
\end{tabular}


we can consume as little energy as possible on the premise of the guarantee of economic benefit.

The positive driving force from construction on energy efficiency in Beijing and Hebei accounts for that energy consumption in construction bringing about considerable economic benefits, which is beneficial to boosting energy efficiency. However, construction in Tianjin has a negative contribution value on energy efficiency. To be more specific, energy consumption of construction in Tianjin added from 0.38 million to 1.61 million tons with an average annual growth rate of $23.07 \%$, while GDP rose at an average annual growth rate of $17.29 \%$, from 17.71 billion to 54.08 billion yuan in 2005-12 based on data analysis. Thus we can see that the rapid development of construction in Tianjin relies on a great deal of energy consumption resulting in low-lying energy efficiency.

In addition, transportation, storage, postal services, wholesale retail trade, and food services and others have a positive impact on energy efficiency in diverse areas. Nonetheless, it is evident that transportation, storage, and postal services have the lowest contribution value in each region. Meanwhile, this reflects that transportation, storage, and postal services in every region still can be improved, which is to say we must ensure growth of GDP in transportation, storage, and postal services on the basis of reducing energy consumption to improve overall energy efficiency. On the contrary, wholesale retail trade, food services, and others have relatively high contribution values, which illustrates that the growth rate of economic output far surpasses that of energy consumption in these sectors, that is, these sectors have the ability to boost overall energy efficiency. Thus, we can sum up that the drastic expansion of tertiary industry can improve overall energy efficiency to a large extent.

As we all know, various industrial structures possess their own specific influence on energy efficiency from diverse provinces. It is apparent that the more reasonable an industrial structure is, the greater the regional energy efficiency. Table 4 describes the impact of different sectors

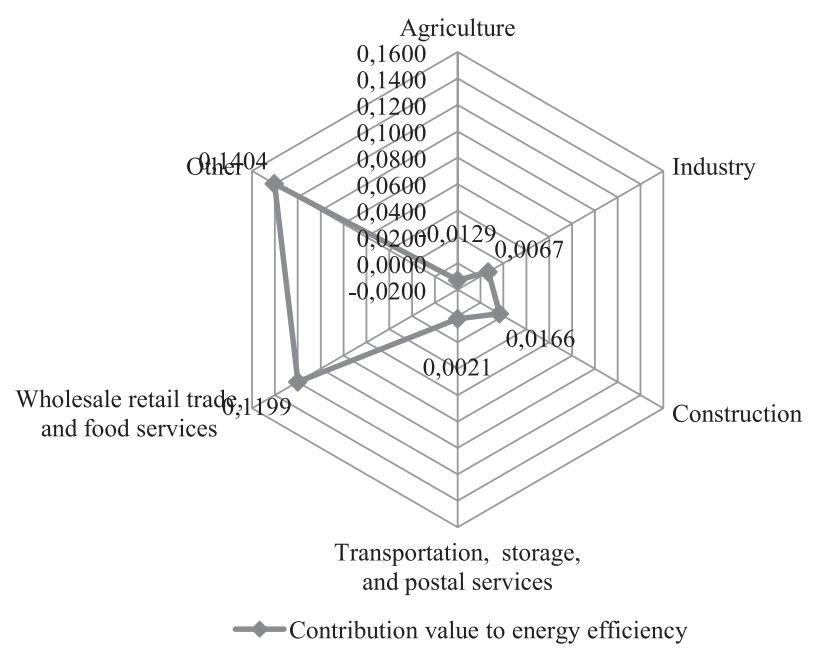

Fig. 11. Contributions of industrial structure in the BeijingTianjin-Hebei to energy efficiency (2005-2012). in various regions on energy efficiency in detail. Besides, the specific influence of six sectors on the overall energy efficiency in the BTH region is depicted in Fig. 11, in which we can find that other sectors with a contribution value of 0.1404 impersonates the leading positive driving force on the overall energy efficiency in the BTH region, followed by wholesale retail trade, food services $(0.1199)$, construction (0.0166), industry (0.0067) transportation, storage, and postal services (0.0021), while agriculture $(-0.0129)$ has a negative impact.

Combining Table 4 with Fig. 11 makes it clear that each sector in Beijing exerts a positive driving function on energy efficiency. Apart from construction, the remaining sectors in Tianjin produce a positive driving force on energy efficiency, whereas most sectors in Hebei play positive roles on energy efficiency except for agriculture. Furthermore, the majority of sectors in the BTH region have positive impacts on energy efficiency, excluding agriculture.

Due to industry characteristics, wholesale retail trade, food services, and other sectors have high energy efficiency. We can easily know that industry and transportation present very small contribution values on energy efficiency due to the low energy utilization efficiency in spite of a huge array of energy consumption.

In the future, we should put special stress on regulating industry and transportation, storage, and postal services in each province on account of their own characteristics in every sector, speeding up the industrial structure adjustment so as to boost overall energy efficiency in the $\mathrm{BTH}$ region.

In accordance with factor decomposition, this research computes the overall contribution values of diverse factors on energy efficiency in the BTH region in the scope of 2005-12. On the whole, the total effect of economic output, carbon productivity, carbon emission coefficient, and energy structure produces a positive driving force on overall energy efficiency in the BTH region, whereas the total effect of energy intensity and reciprocation of per capita energy consumption plays a negative role. As is demonstrated in Fig. 12, economic output effect is the primary driver on energy efficiency with a proportional contribution of $139.57 \%$, followed by carbon productivity effect $(94.55 \%)$, carbon emission coefficient effect

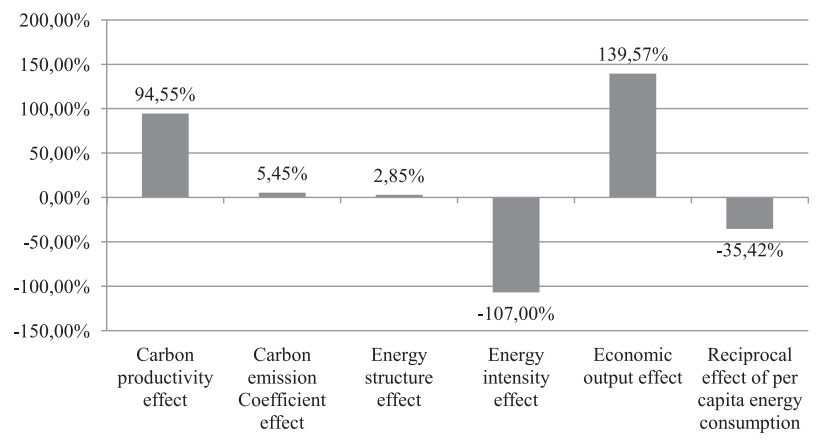

Fig. 12. The contribution of each effect on energy efficiency in the Beijing-Tianjin-Hebei (2005-2012). 
$(5.45 \%)$, and energy structure effect $(2.85 \%)$. In contrast, energy intensity effect - whose contribution reaches $-107.00 \%$ - presents the leading negative impact, while the reciprocal effect of per capita energy consumption $(-35.42 \%)$ is the next in importance.

\section{Conclusions and Policy Implications}

This research aims at identifying the cardinal impact factors governing energy efficiency in the BTH region so as to come up with an array of related policy recommendations on boosting energy efficiency. We break down energy efficiency into carbon productivity effect, carbon emission coefficient effect, energy structure effect, energy intensity effect, economic output effect, and the reciprocal effect of per capita energy consumption by adopting LMDI additive decomposition. More specifically, the impact factors governing energy efficiency in the BTH region of China comprise a thorough inquiry from different sectors and various regions. There is only a little literature on decomposition analyses of energy efficiency in the BTH region. Notwithstanding at present, this research makes a significant contribution to providing comprehensive knowledge in this field, especially when involved with different sectors and various parts of the BTH region.

Based on the decomposition analysis of energy efficiency in the BTH region within the scope of 2005-12, we can summarize certain empirical conclusions.

1. Energy efficiency appears as an annual increase in the basic tendency in all regions, including Beijing, Tianjin, and Hebei during 2005-12. In particular, energy efficiency in Beijing emerges with the fastest growth, followed by Tianjin and Hebei. Therefore, it can be drawn that we ought to stress Hebei in order to improve the overall energy efficiency in the BTH region.

2. The results indicate that different factors in various regions exert a diverse impact on energy efficiency by making decomposition on energy efficiency in Beijing, Tianjin, and Hebei, respectively.

For instance, the carbon productivity effect acts as a top-drawer positive driver on energy efficiency in Beijing, followed by a reciprocal effect per capital energy consumption, economic output effect, and carbon emission coefficient effect, while energy intensity effect is the primary negative driving force on energy efficiency, and energy structure effect pertains to the next in importance as well.

In addition, economic output effect impersonates the leading positive driving function on energy efficiency in Tianjin, followed by carbon productivity effect, energy structure effect and carbon emission coefficient effect. In contrast, energy intensity effect produces the overriding positive driving action on energy efficiency, followed by reciprocal effect per capital energy consumption.

Besides, economic output effect has the principal positive impact on energy efficiency in Hebei, followed by energy structure effect and carbon productivity effect, whereas reciprocal effect per capital energy consumption is the cardinal negative driver, energy intensity effect, and carbon emission coefficient effect following.

3. Generally speaking, from a regional integration aspect, economic output effect played a paramount role on overall energy efficiency in the BTH region during 2005-12, followed by carbon productivity effect, carbon emission coefficient effect, and energy structure effect. On the contrary, energy intensity effect is the foremost negative driving force, while reciprocal effect per capital energy consumption is not far behind.

4. From a sector standpoint, we can see that each sector plays a positive part in energy efficiency in Beijing by analyzing the impact of six sectors on energy efficiency in different regions during 2005-12. Meanwhile, construction in Tianjin has a negative impact on energy efficiency, as does agriculture in Hebei.

Furthermore, other sectors exert the most significant positive impact on overall energy efficiency in the BTH region, followed by wholesale retail trade, food services, construction, industry, transportation, storage, and postal services, while agriculture is just the opposite.

Eventually, we came up with a few pertinent recommendations as follows:

1. The Chinese government ought to try its best to break down regional protectionism, build a government management mechanism for BTH regional integration, step up industrial cooperation in the BTH region, and encourage the attraction of investments in the region so as to collectively achieve economic integration.

2. China must quicken the pace toward modulating the industrial structure in the BTH region. In view of the situation that coal is the dominating source of energy consumption, followed by oil (while natural gas occupies the smallest proportion), we should focus on improving the proportion of clean energy consumption. In addition, the Beijing government must make more efforts to expand energy import and encourage largescale use of natural gas in order to strictly control coal consumption. Tianjin province should take advantage of its oil resources to boost the use of clean energy by applying a petrolic conversion technology so that coal consumption has a chance to decrease continuously. Meanwhile, Hebei province, as the primary area in the production and consumption of coal, has an obligation to popularize natural gas on a large scale by introducing the natural gas technology of Beijing and reducing the low-efficiency way of direct coal-burning for restraining coal consumption in order to improve energy efficiency from origin.

3. Due to resource-intensive industry as the leading industry in the BTH region, Hebei and Tianjin had better lay emphasis on strengthening rectification in heavy energy-consumption enterprises, developing new industries and speeding up industrial restructuring. Hebei ought to undertake transferring industry of Beijing and Tianjing rationally. At the same time, the country should provide certain timely financial assistance to Hebei to better develop modern 
agriculture. According to the respective characteristics of different provinces, it is apparent that Beijing should pay attention to the tertiary industry while Tianjin and Hebei had better put special stress on modern manufacturing industry. But in the long term, if we intend to boost overall energy efficiency, we should emphasize prompting technological innovation in industry and transportation, storage, and postal services so that we can consume as little energy as possible on the basis of the guarantee of great economic benefit.

4. The government is duty-bound to strengthen its efforts on energy conservation and emission reduction and green procurement so as to drive the consumption of clean and highly efficient products by an act of government procurement, such as the extensive utilization of clean-energy vehicles, the generalization of high-efficiency electrical equipment, and the execution of building energy management, etc.

\section{Acknowledgements}

This study was supported by the National Social Science Foundation of China (NSSFC) (grant No. 15BGL145), the National Natural Science Foundation of China (NSFC) (grant No. 71471061), Fundamental Research Funds for the Central Universities (No. 2015ZD33), and the Philosophy and Social Science Research Base of Hebei Province.

\section{References}

1. NBSC (National Bureau of Statistics of China). China Statistics Yearbook of 2014. China Statistics Press; 2014.

2. NBS (National Bureau of Statistics of the People's Republic of China). China energy statistical yearbook 2005-2013. China Statistics Press; 2013.

3. ANG B.W., ZHANG F.Q. A survey of index decomposition analysis in energy and environmental studies. Energy, 25, 1149, 2000.

4. LIAO H., WEI Y.M. Chinas energy consumption: a perspective from Divisia aggregation approach. Energy, 35, 28,2010

5. ZHAO X., LI N., MA C. Residential energy consumption in urban China: a decomposition analysis. Energy Policy, 41, 644, 2012.

6. KAHRL F., ROLAND-HOLST D., ZILBERMAN D. Past as Prologue? Understanding energy use in post-2002 China. Energy Econ. 36, 759, 2012.

7. ANG B.W. Decomposition analysis for policymaking in energy: which is the preferred method? Energy Policy, 32, 1131, 2004.

8. ANG B.W., LIU F.L. A new energy decomposition method: perfect in decomposition and consistent in aggregation. Energy, 26, 537, 2001.

9. ANG B.W. The LMDI approach to decomposition analysis: a practical guide. Energy Policy, 33, 867, 2005.

10. XU M., LI R., CRITTENDEN J.C., CHEN Y.S. $\mathrm{CO}_{2}$ emissions embodied in China's exports from 2002 to 2008: a structural decomposition analysis. Energy Policy, 39, 7381, 2011.
11. DU H.B., GUO J.H., MAO G.Z., SMITH A.M., WANG X.X., WANG Y. $\mathrm{CO}_{2}$ emissions embodied in China-US trade: Input-output analysis based on the emergy/dollar ratio. Energy Policy, 39, 5980, 2011.

12. WANG Y., ZHAO H.Y., LI L.Y., LIU Z., LIANG S. Carbon dioxide emission drivers for a typical metropolis using inputoutput structural decomposition analysis. Energy Policy, 58, 312,2013

13. ANG B.W., ZHANG F.Q. Inter-regional comparisons of energy-related $\mathrm{CO}_{2}$ emissions using the decomposition technique. Energy, 24, 297, 1999.

14. ZHANG J.Y., ZHANG Y., YANG Z.F., FATH B.D., LI S.S. Estimation of energy-related carbon emissions in Beijing and factor decomposition analysis. Ecol. Model. 252, 258, 2013.

15. SHAO C.F., GUAN Y., WAN Z., GUO C.X., CHU C.L., JU M.T. Performance and decomposition analyses of carbon emissions from industrial energy consumption in Tianjin, China. J. Clean. Prod. 64, 590, 2013.

16. WANG W.X., KUANG Y.Q., HUANG N.S. Study on the Decomposition of Factors Affecting Energy-Related Carbon Emissions in Guangdong Province, China. Energies, 4, 2249, 2011

17. O'MAHONY T. Decomposition of Ireland's carbon emissions from 1990 to 2010: An extended Kaya identity. Energy Policy, 59, 573, 2013.

18. WANG C.J., WANG F., ZHANG H.O. Carbon Emissions Decomposition and Environmental Mitigation Policy Recommendations for Sustainable Development in Shandong Province. Sustainability, 6, 8164, 2014.

19. CHEN Y.N., LIN S. Study on factors affecting energyrelated per capita carbon dioxide emission by multi-sectoral of cities: a case study of Tianjin. Natural Hazards, 77, 833, 2015.

20. ANG B.W., ZHANG F.Q., CHOI K.H. Factorizing changes in energy and environmental indicators through decomposition. Energy, 23, 489, 1998.

21. WANG C., CHEN J., ZOU J. Decomposition of energy-related $\mathrm{CO}_{2}$ emission in China: 1957-2000. Energy, 30, 73, 2005.

22. WEN L., CAO Y., WENG J.F. Factor decomposition analysis of Chinass energy-related $\mathrm{CO}_{2}$ emissions using extended STIRPAT model. Pol. J. Environ. Stud. 24, 2261, 2015.

23. ZHOU G.H., CHUNG W., ZHANG Y.X. Carbon dioxide emissions and energy efficiency analysis of China's regional thermal electricity generation. J. Clean. Prod. 83, 173, 2014.

24. BALEZENTIS A. The energy intensity in Lithuania during 1995-2009: A LMDI approach. Energy Policy, 39, 7322, 2011.

25. WEN L., LIU Y.J. The peak value of carbon emissions in the Beijing-Tianjin-Hebei region based on the STIRPAT model and scenario design. Pol. J. Environ. Stud. 25, 823, 2016.

26. LIN B.Q., LONG H.Y. How to promote energy conservation in China's chemical industry. Energy Policy, 73, 93, 2014.

27. WANG Z.H., ZENG H.L., WEI Y.M., ZHANG Y.X. Regional total factor energy efficiency: an empirical analysis of industrial sector in China. Appl Energy, 97, 115, 2012.

28. SHAO C., GUAN Y., WAN Z., CHU C., JU M. Performance analysis of $\mathrm{CO}_{2}$ emissions and energy efficiency of metal industries in China. J Environ Manag. 134, 30, 2014.

29. HE F., ZHANG Q., LEI J., FU W., XU X. Energy efficiency and productivity change of Chinass iron and steel industry: accounting for undesirable outputs. Energy Policy, 54, 204, 2012.

30. LI Y., SUN L., FENG T. How to reduce energy intensity in China: a regional comparison perspective. Energy Policy, 61, 513, 2013. 
31. YUAN Y., ZHA J. Study on the supply capacity of crop residue as energy in rural areas of Heilongjiang province of China. Renew Sustain Energy Rev. 38, 526, 2014.

32. WU Y. Energy intensity and its determinants in Chinass regional economies. Energy Policy, 41, 703, 2012.

33. LEE J.J. Can we accelerate the improvement of energy efficiency in aircraft systems? Energy Convers Manage. 51, 189, 2010.
34. HE H., JIM C.Y. Coupling model of energy consumption with changes in environmental utility. Energy Policy, 43, 235, 2012.

35. IPCC, Intergovernmental Panel on Climate Change Guidelines for National Greenhouse Gas Inventories, OECD, Paris, France, 1999. 
